\title{
CHARACTERISTICS AND APPLICATION OF SILVER NANOPARTICLES IN THE FOOD INDUSTRY - REVIEW
}

\author{
Anna Mikołajczuk-Szczyrba ${ }^{1 *}$, Marek Kieliszek², Liviu Giurgiulescu ${ }^{3}$, Barbara Sokołowska ${ }^{1}$ \\ ${ }^{1}$ Prof. Wacław Dabrowski Institute of Agricultural and Food Biotechnology, \\ Department of Microbiology, 36 Rakowiecka St., 02-532 Warsaw, Poland; \\ ${ }^{2}$ Institute of Food Sciences, Department of Food Biotechnology and Microbiology, \\ Warsaw University of Life Sciences - SGGW, 159C Nowoursynowska St., 02-776 Warsaw, Poland; \\ ${ }^{3}$ Chemistry-Biology Department, Technical University of Cluj Napoca, \\ North Universitary Center of Baia Mare, 76 Victoriei St., Romania \\ *anna.mikolajczuk-szczyrba@ibprs.pl
}

https://doi.org/10.34302/2019.11.4.14

\begin{tabular}{|c|c|}
\hline Article history: & ABSTRACT \\
\hline $\begin{array}{l}\text { Received: } \\
\text { 25 March } 2019 \\
\text { Accepted: } \\
29 \text { November } 2019\end{array}$ & $\begin{array}{l}\text { Nanocolloids are substances that are constantly gaining technological } \\
\text { significance in various industries. Due to their unique properties, they are } \\
\text { also used in a wide variety of fields, including medicine, biotechnology, and } \\
\text { agriculture. It has been proven that nanocolloids act antagonistically on }\end{array}$ \\
\hline $\begin{array}{l}\text { Keywords: } \\
\text { Nanotechnology; } \\
\text { Silver nanoparticles; } \\
\text { Food; } \\
\text { Antibacterial activity. }\end{array}$ & $\begin{array}{l}\text { many different microorganisms. This article highlights some of the } \\
\text { achievements and challenges associated with the use of silver nanocolloids } \\
\text { in the food industry. Currently, research and development programs are } \\
\text { focused on discovering new nanomaterials and nanostructures for novel } \\
\text { applications. Thus, it could be understood that the prospects for the future } \\
\text { are exciting, and more challenges are expected with the continuous increase } \\
\text { in research on these substances. }\end{array}$ \\
\hline
\end{tabular}

\section{Introduction}

Nanotechnology is currently a rapidly growing, interdisciplinary field of science that allows us to obtain products with unique and innovative properties. According to the current definition, nanotechnology is a science that deals with the application, production, and processing of materials at the level of individual atoms and molecules (Singh, 2017; Peters, 2016).

Nanoparticles are objects that have at least one dimension in the range of $1-100 \mathrm{~nm}$. They have the same chemical composition as their macro counterparts but differ in a number of characteristics. Even among the nanoparticles, the optical, magnetic, and thermodynamic properties, as well as the characteristics such as color, solubility, strength, diffusivity, and toxicity, vary (Singh, 2017). In addition, the ultrasmall dimensions and high surface-tovolume ratio of the nanoparticles enable them to acquire new physicochemical properties. Furthermore, the strongly developed specific surface of the nanoparticles affects their adsorption properties and antimicrobial activity (Peters, 2016).

Thanks to the unique properties, nanoparticles are used in medicine and many other industries (Quing, 2018; Fu, 2014). The possibilities of applications of nanoparticles in the agri-food sector cover many fields, including agriculture, food processing and packaging, and the production of dietary supplements (Singh, 2017; Dunkan, 2011). To date, few of the potential applications of nanoparticles have been implemented in the food industry, but many works are still at the research and development stage (Głód, 2014). The reason for 
this is, among others, imprecise legal regulations associated with the use of nanoparticles in the field of food packaging and processing, as well as the lack of accurate toxicological data covering the impact of nanoparticles on the environment and human health. Despite this, the use of nanoparticles in the food industry has increased significantly over the last decade. The largest increase in nanoparticle applications has been recorded in the sector of packaging materials (He, 2016; Carbone, 2016). In the production of food packaging, nanomaterials, metal nanoparticles, and their oxides are most commonly used. An example would be titanium oxide nanoparticles that are used in polymer nanocomposites as a protective factor against the harmful effects of ultraviolet radiation (LIorens, 2012). Currently, the most active area of research in the packaging materials industry is the use of nanoparticles with biocidal properties. Nanoparticles that possess antimicrobial properties include some metals, such as $\mathrm{Cu}, \mathrm{Zn}$, Ti, and Ag. Among them, silver nanoparticles (Ag-NPs) deserve special attention as they exhibit the most effective biocidal activity against a wide range of microorganisms (Carbone, 2016).

\section{Antibacterial activity of silver nanoparticles}

Silver was already known in antiquity due to its antibacterial properties. To prevent diseases, the ancient Greeks covered silverware and placed silver coins in water jars to extend shelf life. For many years, silver compounds have been known to exert a basic protective function against numerous infections and diseases caused by microorganisms (Dunkan, 2011). The intensification of the phenomenon of antibiotic resistance observed for several years has again increased the importance of silver in the fight against microorganisms (Lemire, 2013). Compared with other antimicrobials, which are usually directed at specific groups of organisms, silver has a broad spectrum of antimicrobial activity (Quing, 2018).

The growing importance of silver as a bactericide and the development of nanotechnology have led to the initiation of research into the effectiveness of Ag-NPs in the fight against food pathogens. The results of experimental studies have shown the extremely strong antibacterial activity of Ag-NPs against many bacteria, including those that are foodspoiling and pathogenic to humans. It was confirmed that Ag-NPs have the ability to inactivate and inhibit the growth of numerous bacterial species, including, among others, Escherichia coli, Salmonella enterica Typhimurium, and Listeria monocytogenes. In addition, Ag-NPs have been shown to be toxic to some fungi (e.g. Candida albicans, Aspergillus niger) and viruses (e.g. HIV) (King, 2018; Dunkan, 2011).

Several publications describe the multifaceted action of Ag-NPs on bacterial cells. However, despite thorough analyses, the mechanism of action of Ag-NPs has not been clearly defined yet and remains a subject of research (Quing, 2018). The effect of nanoparticles on bacterial cells was first analyzed in a model $E$. coli species. Due to the action of Ag-NPs, pores (cavities) were formed on bacterial sheaths, which led to the loss of tightness of the wall-called membrane syndrome-and consequently to cell autolysis (Liao, 2019). Subsequent investigations, extended to other bacterial species, have allowed the identification of three basic mechanisms underlying the effect of Ag-NPs on bacterial cells: 1) direct binding to the cell membrane and impairment of its function; 2) interaction with cellular components (e.g. proteins, enzymes, DNA); and 3) induction of oxidative stress by inducing the production of reactive oxygen species (King, 2018; Lemire, 2013).

After anchoring in the cell membrane of bacteria, Ag-NPs cause changes in its structure and function. The electrostatic potential is modified, and the membrane permeability increases. In this way, cell components that are essential for the microorganisms are lost or there occurs an uncontrolled uptake of substances from the environment (Qing, 2018; Liao, 2019). In addition, through electrostatic interactions with the surface of cellular shields, including 
membrane proteins, Ag-NPs can penetrate inside the bacterial cell. Once inside the cell, Ag-NPs react with numerous structures and biomolecules, leading to more extensive damage. Ag-NPs have a high affinity for thiol groups of proteins and cause their denaturation and inactivation. The result is impairment of the activity of important intracellular enzymes (Mihindukulasuriya, 2014). The indirect involvement of Ag-NPs in the inhibition of ATP synthesis as a result of interaction with the proteins participating in its production has also been proven (Qing, 2018). Ag-NPs can react with phosphorus and sulfur contained in DNA leading to serious damage to its structure (Liao, 2019). The mechanism of the biocidal action of Ag-NPs may also be induced by their interaction with ribosomes. Following the interaction, the translation process and protein synthesis are inhibited. Worth changing in the cells of Gramnegative bacteria exposed to Ag-NPs were changes in the signal transduction system. AgNPs have been shown to be responsible for the dephosphorylation of tyrosine residues of protein substrates resulting in the inhibition of signal tradition (Prabhu, 2012).

It should be emphasized that Ag-NPs are a source of silver ions that enhance the antibacterial effect of nanosilver. Silver ions released from Ag-NPs can bind to the functional groups of proteins and enzymes, causing serious effects on bacterial metabolism. In addition, it should be emphasized that Ag-NPs reduce the expression of antioxidant enzymes such as superoxide dismutase, catalase, and glutathione, which play a key role in the antioxidation process (Qing, 2018). Silver ions are also involved in the production of reactive oxygen species, which in increased amounts cause, among others, protein oxidation and lipid peroxidation (He, 2016).

The antibacterial activity of Ag-NPs depends on many factors, including the properties of microorganisms, external conditions (environmental $\mathrm{pH}$, temperature, salinity, presence of oxygen), as well as the size and shape of the nanoparticles themselves. It has been proven that the antibacterial potential of nanosilver increases with a decrease in the diameter of Ag-NPs. Smaller nanoparticles have a relatively larger surface for the release of silver ions and greater protein-binding efficiency and are also easier to pass through the pores in the bacterial membrane. The toxic effects of nanoparticles on microorganisms also depend on their shape: triangular-shaped nanoparticles have a stronger antibacterial effect than the elongated ones (Singh, 2015; LIorens, 2012).

\section{Silver nanoparticles-application in the food industry}

One of the goals set by the food industry is to ensure consumer safety and extend the shelf life of food products. The desire to accomplish the above tasks contributes to finding new solutions for promoting food safety and preventing the spread of pathogenic microorganisms transmitted through contaminated food (Table 2). Proper storage of food products is necessary to achieve these goals, and hence, packaging

materials play an important role in both the food and medical sectors (Olmos, 2018). Innovations in the packaging industry focus on the development of new, active materials that, in addition to providing the basic protective barrier against the negative environmental factors, are capable of maintaining and improving sensory quality and increasing the microbiological safety of the packaged product. In recent years, materials with antimicrobial properties obtained by incorporating Ag-NPs in the polymer structure have been of great interest among researchers (Olmos, 2018; Li, 2017). The active packaging component-nanosilver-interacts directly with food and/or the space around it, limiting or inhibiting the growth of pathogenic and food-spoiling microorganisms (Carbone, 2016; Sharma, 2017). The antibacterial potential of a material containing Ag-NPs is conditioned by many factors. In addition to the size of the nanosilver particles themselves, their concentration in the polymer matrix and the degree of agglomeration are important. To efficiently perform their antimicrobial function, Ag-NPs should be suitably small in size and well 
dispersed in the polymer (without agglomeration) (Rhim, 2014; Lorens et al.,2012).

Table 1. Applications of nanoparticles in the food industry

\begin{tabular}{|c|c|c|c|}
\hline Nanomaterial & Types of food & Tested microorganism & References \\
\hline Polyethylene, AgNPs & Nuts & Bacteria, fungi & Tavakoli et al., 2017 \\
\hline $\begin{array}{l}\text { Low density polyethylene, } \\
\text { AgNPs }\end{array}$ & Barberry & Bacteria & $\begin{array}{l}\text { Valipoor Motlagh et } \\
\text { al., } 2012\end{array}$ \\
\hline $\begin{array}{l}\text { Low density polyethylene, } \\
\mathrm{AgNPs} \mathrm{TiO}_{2}\end{array}$ & Rice & A. flavus & Li et al., 2017 \\
\hline $\begin{array}{l}\text { Polyvinylpyrrolidone, } \\
\text { AgNPs }\end{array}$ & Fresh asparagus & $\begin{array}{l}\text { Psychotrophic bacteria, yeasts and } \\
\text { molds }\end{array}$ & An et al., 2008 \\
\hline Polyvinylchloride, AgNPs & Ground beef & E. coli, S. aureus & Mahdi et al., 2012 \\
\hline Cellulose, AgNPs & Beef meat & $\begin{array}{l}\text { Lactic acid bacteria, } \\
\text { Enterobacteriaceae, Pseudomonas }\end{array}$ & Fernandez et al., 2010a \\
\hline Cellulose, AgNPs & Fresh-cut melon & Bacteria, yeasts & Fernandez et al., 2010b \\
\hline $\begin{array}{l}\text { Hydroxypropylmethylcell } \\
\text { ulose, AgNPs }\end{array}$ & - & E. coli, S. aureus & de Moura et al., 2012 \\
\hline $\begin{array}{l}\text { Cellulose nanofibril, } \\
\text { AgNPs }\end{array}$ & - & S. aureus, E. coli $\mathrm{O} 157: \mathrm{H} 7$ & Yu et al., 2019 \\
\hline Pullulan, AgNPs & Turkey meat & L. monocytogenes, S. aureus & Khalaf et al., 2013 \\
\hline Starch, AgNPs & - & S. aureus, E. coli, C. albicans & Abreu et al., 2015 \\
\hline Chitosan, gelatin, AgNPs & Red grapes & Fungi & Kumar et al., 2018 \\
\hline $\begin{array}{l}\text { Chitosan, Cellulose, } \\
\text { AgNPs }\end{array}$ & - & E. coli, S. aureus & Li et al., 2015 \\
\hline Agar, AgNPs & - & E. coli $\mathrm{O} 157: \mathrm{H} 7$, L. monocytogenes & Rhim et al., 2014 \\
\hline $\begin{array}{l}\text { Agar, banana powder, } \\
\text { AgNPs }\end{array}$ & - & E. coli, L. monocytogenes & Orsuwan et al., 2016 \\
\hline
\end{tabular}

Depending on the material used, an antibacterial packaging can be a synthetic polymer or a biodegradable or edible coating. The latter is composed of natural polymers, usually polysaccharides, lipids, or animal and plant proteins (Shit, 2014). Among the most commonly used artificial polymers, polyethylene (PE), polyvinyl chloride (PVC), and polyvinylpyrrolidone (PVP) deserve a special mention (Carbone, 2016).

In the scientific literature, there are numerous studies on the use of Ag-NPs in packaging materials showing promising results. In one interesting study carried out by Tavakoli et al. (2017), the effect of PE-silver foils on extending the shelf life of four types of nuts (hazelnuts, walnuts, pistachios, and almonds) were examined. Studies have shown that the addition of Ag-NPs to PE packaging significantly reduces the growth of microorganisms. Positive effects were also observed in the case of mold, with a visible decrease in their numbers. Furthermore, the use of packaging made of Ag-NPs was shown to increase the shelf life of nuts by an average of 6 months.

In turn, Valipoor Motlagh et al. (2012) showed that low-density polyethylene (LDPE) films containing Ag-NPs play a significant role in maintaining the microbiological and sensory quality of dried barberry. LDPE foil made with nanosilver showed a strong antimicrobial activity by limiting the growth of bacteria and mold in the tested material. The fruit stored in LDPE foil containing Ag-NPs retained the fresh aroma and red color for about 2-3 weeks longer, compared to the fruit stored in the foil without the addition of Ag-NPs. Li et al. (2017) examined the activity of LDPE film containing $\mathrm{Ag}-\mathrm{NPs} / \mathrm{TiO}_{2}$ against Aspergillus flavus during 
rice storage. Microbiological analyses carried out after 35 days of product storage showed that $\mathrm{LDPE} / \mathrm{Ag}-\mathrm{NPs} / \mathrm{TiO}_{2}$ significantly inhibits mold growth and positively affects the physicochemical properties of rice. Studies were carried out in comparison with the rice stored in pure PE film, which showed no activity against A. flavus. Thus, the synthesized new LDPE/Ag$\mathrm{NPs} / \mathrm{TiO}_{2}$ film seems to be a promising packaging material because contamination of rice with molds, and in particular A. flavus, is the main cause of product loss at the storage stage.

An et al. (2008) conducted a study in which they proved that storing fresh asparagus in the coatings made of PVP with the addition of AgNPs will extend their shelf life by approximately 10 days. It was found that PVP/Ag-NPs coatings significantly reduced the growth of psychrotrophic bacteria, yeast, and mold in the tested vegetable samples. In addition, asparagus samples stored in coatings containing Ag-NPs showed a smaller mass loss and lesser ascorbic acid compared to the control samples stored without the addition of nanosilver. It was also shown that vegetables protected with an Ag-NPs coating maintained a saturated green color longer, which was the result of slower chlorophyll degradation.

Mahdi et al. (2012) evaluated the impact of PVC-nano packaging Ag-NPs on the shelf life of beef minced meat stored at $4^{\circ} \mathrm{C}$. Research results showed a marked improvement in the microbiological quality, primarily a reduction in the growth of $E$. coli. Inhibition of bacterial growth resulted in an extension of the shelf life of meat to 7 days, while the meat stored in traditional packaging deteriorated after 2 days.

In recent years, the use of natural biodegradable materials, which are an alternative to biologically degradable films, is gaining popularity. The use of ecological materials allows limiting the use of plastic films, which constitute a great burden to the natural environment due to long-term decomposition (Shit, 2014). In addition, some natural polymers (e.g. gelatin) can be obtained from the waste and by-products of the agri-food industry, for example, waste from the fishing industry. A number of researchers are using eco-friendly materials as carriers for Ag-NPs. The most commonly used biodegradable polymers for contact with food include cellulose, pullulan, starch, chitosan, and agar (Khalaf, 2013).

Fernandez et al. (2010a) assessed the ability of cellulosic absorbent pads containing Ag-NPs to inhibit microbial growth during the storage of pork. Microbiological analyses showed a significant reduction in the overall count of bacteria. In another work (Fernandez et al. 2010b), the same research team investigated the use of cellulose pads from Ag-NPs in storing fresh pieces of melon. Significant differences in appearance and microbiological quality were observed between the control samples stored without the addition of Ag-NPs and the fruits containing nanosilver rootstocks. The use of antibacterial pads effectively reduced the number of bacteria and yeast in the tested material, thus confirming the broad-spectrum biocidal activity of nanosilver. In addition, the presence of nanosilver rootstocks delayed the aging process of the fruit, probably by blocking the effects of ethylene (Duncan, 2011; Fernandez, 2010b).

De Moura et al. (2012) obtained an active packaging material based on hydroxypropyl methylcellulose and Ag-NPs, which in addition to exhibiting an effective antibacterial activity against E. coli and Staphylococcus aureus, improved the water vapor barrier properties and increased the mechanical strength of the nanocomposite. In addition, the authors determined the relationship between the size of Ag-NPs and their antibacterial activity. Based on the results of the research, it was confirmed that nanoparticles with a smaller diameter $(41 \mathrm{~nm})$ have a stronger bactericidal effect than the particles with a larger diameter $(100 \mathrm{~nm})$. Yu et al. (2019) tested the antibacterial activity of a film composed of cellulose nanofibril and AgNPs against food-pathogenic E. coli O157:H7 and L. monocytogenes. The results showed that the modified nanomaterial had effective antibacterial properties against the bacteria studied, with $E$. coli being more sensitive to nanosilver than $L$. monocytogenes. 
Khalaf et al. (2013) investigated and compared the effectiveness of two pullulan coatings containing, respectively, Ag-NPs and zinc oxide nanoparticles in reducing the occurrence of L. monocytogenes and S. aureus in turkey meat. It was shown that pullulan composites enriched with Ag-NPs exerted a stronger antibacterial activity against the studied pathogens than the pullulan coatings containing zinc oxide.

Abreu et al. (2015) created a film based on starch and Ag-NPs. The resulting nanocomposite inhibited the growth of $S$. aureus, E. coli, and C. albicans.

Kumar et al. (2018) developed an innovative hybrid food film composed of two commonly used biopolymers, chitosan and gelatin, with the addition of Ag-NPs. The researchers evaluated the effectiveness of this nanocomposite in extending the shelf life of red grapes. After 14 days of storage at $37^{\circ} \mathrm{C}$, the fruits protected in chitosan-gelatin-Ag-NPs hybrid foil were characterized by a fresh appearance and smooth surface, whereas grapes stored in a film made of $\mathrm{PE}$ and chitosan-gelatin hybrid without the addition of Ag-NPs had an unpleasant smell and showed mold formation on their surface.

Agar-based films supplemented with AgNPs also have good antimicrobial properties. Rhim et al. (2014) investigated the effect of silver-agar coatings on reducing the growth of two food-borne pathogenic bacteria: E. coli O157:H7 and L. monocytogenes. The authors proved that the control coatings without the addition of nanosilver did not show any antimicrobial activity. In contrast, the coatings supplemented with Ag-NPs exhibited antibacterial properties against the tested pathogens, with a stronger effect against $E$. coli. It was found that the antibacterial activity of the coatings depended on the concentration of AgNPs and the studied bacterial strain. The above result is consistent with the earlier reports revealing the stronger antibacterial activity of Ag-NPs against Gram-negative bacteria than Gram-positive ones. The difference in Ag-NPs activity is caused by the different structures of the wall membrane assembly of both types of bacteria.

\section{Conclusions}

The possibilities of applying nanotechnology in the food industry are extremely promising. In recent years, the use of antibacterial packaging materials made with AgNPs has gained importance. The use of Ag-NPs in polymers used for packaging offers many benefits including, among others, extended shelf life of food products and the prevention of the spread of food-borne pathogens. The use of AgNPs can also reduce the consumption of preservatives. In addition to the above advantages, the negative effects of using AgNPs should also be mentioned. The main threat is related to the possibility of migration of AgNPs from the packaging materials to food products. Thus, there is a real risk of uncontrolled and unconscious consumption of Ag-NPs. However, the toxic effects of the longterm ingestion of low but frequent doses of AgNPs have not yet been studied. Therefore, in order to be able to widely use Ag-NPs in packaging materials, further research is needed to determine every possible negative impact of these materials on human health and the environment.

\section{References}

Abreu, A S., Oliveira, M., de Sa, A., Rodrigues, R.M., Cerqueira, M.A., Machado, A.V. (2015). Antimicrobial nanostructured starch based films for packaging. Carbohydrate Polymers, 129, 127-134.

An, J., Zhang, M., Wang, S., Tang, J. (2008). Physical, chemical and microbiological changes in stored green asparagus spears as affected by coating of silver nanoparticlesPVP. LWT-Food Science and Technology, 41(6), 1100-1107.

Carbone, M., Donia, D.T., Sabbatella, G., Antiochia, R. (2016). Silver nanoparticles in polymeric matrices for fresh food packaging. Journal of King Saud University - Science, 28(4), 273-279. 
De Moura, M.R., Mattoso, L.H., Zucolotto, V. (2012). Development of cellulose-based bactericidal nanocomposites containing silver nanoparticles and their use as active food packaging. Journal of Food Engineering, 109(3), 520-524.

Duncan, T.V. (2011). Applications of nanotechnology in food packaging and food safety: barrier materials, antimicrobials and sensors. Journal of Colloid and Interface Science, 363(1), 1-24.

Fernandez, A., Picouet, P., Lloret, E. (2010a). Cellulose-silver nanoparticle hybrid materials to control spoilage-related microflora in absorbent pads located in trays of fresh-cut melon. International Journal of Food Microbiology, 142(1-2), 222-228.

Fernandez, A., Picouet, P., Lloret, E. (2010b). Reduction of the spoilage-related microflora in absorbent pads by silver nanotechnology during modified atmosphere packaging of beef meat. Journal of Food Protection, 73(12), 2263-2269.

Fu, P.P., Xia, Q., Hwang, H.M., Ray, P.C., Yu, H. (2014). Mechanisms of nanotoxicity: generation of reactive oxygen species. Journal of Food and Drug Analysis, 22(1), 64-75.

He, X., Hwang, H.M. (2016). Nanotechnology in food science: Functionality, applicability, and safety assessment. Journal of food and drug analysis, 24(4), 671-681.

Khalaf, H.H., Sharoba, A.M., El-Tanahi, H.H., Morsy, M.K. (2013). Stability of antimicrobial activity of pullulan edible films incorporated with nanoparticles and essential oils and their impact on turkey deli meat quality. Food Dairy Science, 4, 557573.

King, T., Osmond-McLeod, M.J., Duffy, L.L. (2018). Nanotechnology in the food sector and potential applications for the poultry industry. Trends in Food Science \& Technology, 72, 62-73.

Kumar, S., Shukla, A., Baul, P P., Mitra, A., Halder, D. (2018). Biodegradable hybrid nanocomposites of chitosan/gelatin and silver nanoparticles for active food packaging applications. Food Packaging and Shelf Life, 16, 178-184.

Lemire, J.A., Harrison, J.J., Turner, R.J. (2013). Antimicrobial activity of metals: mechanisms, molecular targets and applications. Nature Reviews Microbiology, 11(6), 371.

Li, L., Zhao, C., Zhang, Y., Yao, J., Yang, W., $\mathrm{Hu}$, Q., Wang C., Cao, C. (2017). Effect of stable antimicrobial nano-silver packaging on inhibiting mildew and in storage of rice. Food Chemistry, 215, 477-482.

Liao, S., Zhang, Y., Pan, X., Zhu, F., Jiang, C., Liu, Q., Cheng, Z., Dai, G., Wu, G.,Wang, L., Chen, L. (2019). Antibacterial activity and mechanism of silver nanoparticles against multidrug-resistant Pseudomonas aeruginosa. International Journal of Nanomedicine, 14, 1469.

Llorens, A., Lloret, E., Picouet, P.A., Trbojevich, R., Fernandez, A. (2012). Metallic-based micro and nanocomposites in food contact materials and active food packaging. Trends in Food Science \& Technology, 24(1), 19-29.

Mahdi, S. S., Vadood, R., Nourdahr, R. (2012). Study on the antimicrobial effect of nanosilver tray packaging of minced beef at refrigerator temperature. Global Veterinaria, 9(3), 284-289.

Mihindukulasuriya, S.D.F., Lim, L.T. (2014). Nanotechnology development in food packaging: A review. Trends in Food Science \& Technology, 40(2), 149-167.

Valipoor Motlagh, N., Hamed Mosavian, M.T., Mortazavi, S. A. (2013). Effect of polyethylene packaging modified with silver particles on the microbial, sensory and appearance of dried barberry. Packaging Technology and Science, 26(1), 39-49.

Olmos, D., Pontes-Quero, G., Corral, A., González-Gaitano, G., González-Benito, J. (2018). Preparation and characterization of antimicrobial films based on LDPE/Ag nanoparticles with potential uses in food and health industries. Nanomaterials,8(2), 60.

Orsuwan, A., Shankar, S., Wang, L.F., Sothornvit, R., Rhim, J.W. (2016). 
Preparation of antimicrobial agar/banana powder blend films reinforced with silver nanoparticles. Food Hydrocolloids, 60, 476485.

Peters, R.J., Bouwmeester, H., Gottardo, S., Amenta, V., Arena, M., Brandhoff, P., Marvin, J.P.H., Mech, A., F.B., Moniz, Pseudo, L.Q., Rauscherde, H., Schoonjans, R., Undas, A.K., Vettori, V.M., Weigel, S., Aschberger, K. (2016). Nanomaterials for products and application in agriculture, feed and food. Trends in Food Science \& Technology, 54, 155-164.

Prabhu, S., Poulose, E.K. (2012). Silver nanoparticles: mechanism of antimicrobial action, synthesis, medical applications, and toxicity effects. International Nano Letters, 2(1), 32.

Yun'an Qing, L.C., Li, R., Liu, G., Zhang, Y., Tang, X., Wang, J., Liu, H., Qin, Y. (2018). Potential antibacterial mechanism of silver nanoparticles and the optimization of orthopedic implants by advanced modification technologies. International Journal of Nanomedicine, 13, 3311-3327.

Rhim, J.W., Wang, L.F., Lee, Y., Hong, S.I. (2014). Preparation and characterization of bio-nanocomposite films of agar and silver nanoparticles: laser ablation method. Carbohydrate Polymers, 103, 456-465.

Sharma, C., Dhiman, R., Rokana, N., Panwar, H. (2017). Nanotechnology: an untapped resource for food packaging. Frontiers in Microbiology, 8, 1735.

Shit, S.C., Shah, P.M. (2014). Edible polymers: Challenges and opportunities. Journal of Polymers, 2014. Article ID 427259

Singh, R., Shedbalkar, U.U., Wadhwani, S.A., Chopade, B. A. (2015). Bacteriagenic silver nanoparticles: synthesis, mechanism, and applications. Applied Microbiology and Biotechnology, 99(11), 4579-4593.

Singh, T., Shukla, S., Kumar, P., Wahla, V., Bajpai, V.K., Rather, I.A. (2017). Application of nanotechnology in food science: perception and overview. Frontiers in Microbiology, 8, 1501.
Tavakoli, H., Rastegar, H., Taherian, M., Samadi, M., Rostami, H. (2017). The effect of nano-silver packaging in increasing the shelf life of nuts: An in vitro model. Italian Journal of Food Safety, 6(4), 6874.

Yu, Z., Wang, W., Kong, F., Lin, M., Mustapha, A. (2019). Cellulose nanofibril/silver nanoparticle composite as an active food packaging system and its toxicity to human colon cells. International Journal of Biological Macromolecules, 129, 887-894. 